\title{
A Hybrid Multicriteria Decision Making Methodology Based on Type-2 Fuzzy Sets For Selection Among Energy Storage Alternatives
}

\author{
Betül Özkan ${ }^{1}$, İhsan Kaya ${ }^{1}$, Ufuk Cebeci*2 ${ }^{2}$, Hüseyin Başlıgil ${ }^{1}$ \\ ${ }^{\text {I} Y i l d i z ~ T e c h n i c a l ~ U n i v e r s i t y ~ D e p a r t m e n t ~ o f ~ I n d u s t r i a l ~ E n g i n e e r i n g ~} 34349$ Besiktas, Istanbul- Turkey \\ ${ }^{2}$ Istanbul Technical University Department of Industrial Engineering 34367 Maçka, Istanbul- Turkey
}

Received 17 January 2014

Accepted 23 July 2015

\begin{abstract}
Energy storage alternatives that help storing excess energy and then using it when the system needs it has become more important in recent years. Determination of the most suitable energy storage alternative can be analyzed by using multi criteria decision making (MCDM) techniques. There are many criteria that affect the best energy storage alternative and the aims are contrasting so, MCDM methodology is a good approach to solve these problems. In this paper, a hybrid MCDM methodology that consists of analytic hierarchy process (AHP) and TOPSIS based on type-2 fuzzy sets is proposed. To obtain more flexible evaluation and more precise results the proposed methodology combines type- 2 fuzzy AHP that used to determine the weights of criteria and type-2 fuzzy TOPSIS methodology that analyzes the alternatives with respect to criteria and weights. The proposed methodology has been used to determine the most suitable energy storage alternatives. For this aim, 6 electrical energy storage alternatives are considered with a hierarchical structure of 4 main and 18 subcriteria. According to results obtained the best electrical energy storage alternative is determined as compressed air energy storage.
\end{abstract}

Keywords: Electrical energy storage, type-2 fuzzy sets, AHP, TOPSIS, MCDM

\section{Introduction}

Energy storage in a power system can be defined as any installation or method, usually subject to independent control, with the help of which it is possible to store energy generated in the power system, keep it stored and use it in the power system when necessary. ${ }^{1}$ Energy storage has been identified as one of solutions to limit the capacity of reserve generation needed and which also can defer the expansion of transmission and distribution assets. ${ }^{2}$ Renewable sources of energy, such as wind and solar, have gained attention over the last few decades as key components to building a clean electric grid. ${ }^{3}$

*Corresponding Author:

E-mails: cebeciu@itu.edu.tr, ufuk cebeci@yahoo.com (U.

Cebeci)

Tel: +90 -212-293 1300 Ext. 2079

Fax: $+90-212-2407260$
Adequate sizing of energy storage is also required to efficiently integrate renewable resources and justify the cost of storage deployment over the more conventional alternatives. ${ }^{4}$

Multi-criteria decision making (MCDM) is one of the growing areas in operation research and it was described as the most well-known branch of decision making. ${ }^{5}$ MCDM methods deal with the process of making decisions in the presence of multiple objectives and the solution. They are highly dependent on decision maker's preferences. ${ }^{6}$ MCDM quantifies each evaluation criterion and applies scientific methods and skills to carry on multi-criteria decisionmaking analysis, so as to evaluate each alternative and then the best alternative that conforms to the decision maker's ideal under several alternatives and criteria. ${ }^{7}$

MCDM techniques can be applied on different fields such as manufacturing systems, technology investments, water and agriculture, energy planning, 


\section{B. Ozkan et al.}

economics and management. ${ }^{6,7}$ Determining on the best energy storage alternative is considered as a MCDM because many criteria have been evaluated simultaneously and there can be contrasting goals for different alternatives.

The theory of fuzzy sets is introduced in problems of MCDM as an effective approach to treat vagueness, lack of knowledge and ambiguity inherent in the human decision making processes. ${ }^{8}, 30$ Generally MCDM problems include both quantitative and qualitative criteria that use imprecise data and human judgments so, the fuzzy set theory can be used to solve these problems. To deal with imprecise information or even ill-structured decision problems, Zadeh (1965) developed the fuzzy set theory as a modeling tool. ${ }^{9}$ In many cases, the decision maker (DM) has imprecise information about the alternatives with respect to an attribute. The classical MCDM methods cannot effectively handle problems with such imprecise information. The fuzzy set theory is a powerful tool to handle imprecise data and fuzzy expressions that are more natural for humans than rigid mathematical rules and equations. ${ }^{5}$ So, we propose to adopt fuzzy set theory in our methodology.

Type-2 fuzzy sets were introduced by Zadeh, as an extension of the concept of an ordinary fuzzy set. Type-2 fuzzy sets have been regarded as one way to increase the fuzziness of relation and increased description means increased ability to handle inexact information in a logically correct manner. ${ }^{10}$ Type-2 fuzzy sets are described by both primary and secondary membership to provide more degrees of freedom and flexibility, and they are three dimensional. Therefore, type-2 fuzzy sets have the advantage of modeling uncertainty more accurately compared with type-1 fuzzy sets. ${ }^{11}$ Type-2 fuzzy sets have been used for multi-criteria decision making (MCDM) problems in literature. Kiliç and Kaya ${ }^{22}$ proposed a MCDM method for investment project evaluation in Turkey that consists of type-2 fuzzy AHP and type-2 fuzzy TOPSIS methods. Çebi and Otay ${ }^{23}$ solved facility location selection problem by using multiple criteria decision making technique fuzzy TOPSIS with interval type- 2 fuzzy sets. The proposed approach is applied to a cement factory site selection problem. Erdogan and Kaya ${ }^{24}$ proposed an integrated multi-criteria decision making (MCDM) methodology based on type-2 fuzzy sets for selection among energy alternatives. Kahraman et al. ${ }^{25}$ developed an interval type-2 fuzzy AHP method together with a new ranking method for type-2 fuzzy sets. They applied the developed model to a supplier selection problem. Chen ${ }^{26}$ developed an ELECTRE based outranking method for multiple criteria decision making within the environment of interval type-2 fuzzy sets. The proposed methodology is applied to a supplier selection problem and a comparison is done with other approaches. Abdullah and Najib ${ }^{27}$ proposed an interval type-2 fuzzy sets AHP model. They introduced a new preference scale and approached a new method to calculate weight of priority by applying TOPSIS equation. The proposed model was illustrated by a numerical example of work safety evaluation. Erdogan and Kaya ${ }^{31}$ proposed a MCDM methodology based on type-2 fuzzy sets for selecting the best alternative fuel bus in Istanbul. Chen et al. ${ }^{28}$ developed an extended QUALIFLEX method for multiple criteria decision making problems based on interval type-2 fuzzy sets. They applied the proposed method to a medical decision making problem. Kilic and Kaya ${ }^{29}$ proposed a new city-ranking model for development agencies operating in Turkey. To address ambiguities and relativities in real-world scenarios more conveniently, type-2 fuzzy sets and crisp sets had been simultaneously used in multicriteria decision making (MCDM) process of grants allocation.

In this paper to determine the best electrical energy storage alternative a hybrid fuzzy multi criteria decision making methodology is proposed. The hybrid fuzzy methodology consists of two MCDM techniques, type-2 fuzzy AHP and type-2 fuzzy TOPSIS. Using this hybrid methodology has the advantage that we can first determine criteria and subcriteria weights by using AHP and then put these weights into the TOPSIS methodology because TOPSIS methodology needs the criteria weights to obtain the best electrical energy storage alternative. To deal better with vague situations and to get more accurate results, type-2 fuzzy sets are used in the proposed methodology. To the best of our knowledge, there is no a hybrid MCDM methodology based on fuzzy type-2 sets for evaluating electrical energy storage alternatives. The proposed methodology is developed to determine on the best electrical energy storage technology. For this aim, six potential electrical energy storage technologies are considered and to evaluate the alternatives 4 main criteria and 16 sub-criteria are identified. The weights of main and sub-criteria are determined by using AHP based on type-2 fuzzy sets. The obtained weights are used in the type-2 fuzzy TOPSIS method to evaluate the alternatives.

The rest of the paper is organized as follows: Electrical energy storage technologies are briefly explained in Section 2. Section 3 briefly explains type-2 fuzzy sets, type-2 fuzzy AHP and type-2 fuzzy TOPSIS 
methodologies. The proposed methodology is detailed with an application and then a sensitivity analysis is conducted into Section 4. The results obtained and future research directions are discussed into Section 5.

\section{Electrical Energy Storage Technologies}

There are different electrical energy storage technologies that have different characteristics. Electrical energy storage refers to a process of converting electrical energy from a power network into a form that can be stored for converting back to electrical energy when needed. ${ }^{12}$ Electrical energy storage systems can contribute to improve the efficiency of power systems. ${ }^{13}$ The most common technologies are briefly explained in this section.

\subsection{Pumped hydro energy storage (PHES)}

Pumped Hydro Energy Storage (PHES) technology is based on using two water reservoirs at different heights. In charging mode, the water is pumped from the lower to the upper reservoir and in discharging mode, the water flows from the upper into the lower reservoir, driving the reversible turbines and producing electricity. ${ }^{14}$ The amount of stored energy is proportional to the height difference between the two reservoirs and the volume of water stored. In general, the life time of PHES is around 30-50 years, with around trip efficiency of $65-75 \%$ and power capital costs of 500-1500 Euros/kW and 10-20 Euros/kWh (1). This is the most common storage system in the electricity sector. ${ }^{14}$

\subsection{Compressed air energy storage (CAES)}

Compressed air energy storage is a promising technology of energy storage due to its high efficiency. The operation of a conventional compressed air energy storage system is described as follows : Excess electricity during off-peak hours is used to drive a 2stage compressor with intercooling. After the compression, the compressed air (40-70 bars) is led to an after-cooler before it gets stored in an underground storage reservoir. At peak hours ,a combustion chamber is employed in order to heat-up stored air and, as a result, to obtain increased power during the expansion process (expansion with reheating). ${ }^{15}$ Compressed Air Energy Storage (CAES) has been shown to be attractive for providing regulating reserve and leveling power imbalances hourly and daily (2). Capital costs for CAES depend on the underground storage conditions, ranging typically between $\$ 400$ and $\$ 800$ per $\mathrm{kW}$ Since the self-discharge of the system is very low, CAES is considered long term time scale storage installations which can compete with PHS. CAES and PHS are the only storage technologies that are currently suitable for large scale power and high energy storage applications. ${ }^{1}$

\subsection{Battery energy storage (BES)}

A battery cell includes 4 main parts; the anode (negative electrode) provides electrons to the load and is oxidized during the electrochemical reaction; the cathode (positive electrode) accepts electrons and is reduced during the reaction; the electrolyte provides the medium for transfer of electrons between the anode and the cathode and the separators between positive and negative electrodes for electrical insulation. ${ }^{1}$

\subsubsection{Lead-acid battery}

Lead-acid battery is the most mature and the cheapest energy storage device of all the battery technologies available. ${ }^{1}$ The disadvantages of lead-acid batteries are the poor low-temperature performance, low durability and environmental concerns due to the use of lead. ${ }^{14}$

\subsubsection{Sodium sulphur battery}

Sodium sulphur battery is a high temperature battery, its working temperature is about $300^{\circ} \mathrm{C}^{14}$ ) When compared with other battery technologies sodium sulphur batteries have more energy density, a long cycle capability, high efficiency, no self-discharge, low maintenance and $99 \%$ recyclability. ${ }^{1}$

\subsubsection{Nickel-based battery}

The nickel based batteries are mainly the nickelcadmium (NiCd), the nickel-metal hybride (NiMH) and the nickel-zinc (NiZn) batteries. All three types use the same material for positive electrode and the electrolyte which is nickel hydroxide and an aqueous solution of potassium hydroxide with some lithium hydroxide.

\subsubsection{Lithium-based battery}

Lithium-based batteries are widely used in small applications, such as mobile phones and portable electronic devices. ${ }^{1}$ Lithium based batteries have a very high efficiency and reliability, a good energy density and a slow self-discharge rate but they are expensive. ${ }^{14}$

\subsection{Flywheel energy storage}

Flywheels store kinetic energy in a rotating mass. ${ }^{16}$ They store energy in the angular momentum of a spinning mass. ${ }^{12}$ The major advantage of flywheel is that they have a long life capable of providing several hundreds of thousands of full charge-discharge cycles. The efficiency of flywheels is high and typically in the range of $90-95 \%{ }^{12}$ Flywheels are adequate for 


\section{B. Ozkan et al.}

interchanging medium and high powers ( $\mathrm{kWtoMW}$ ) during short periods (seconds) with high energy efficiency in the range of $90-95 \% .^{1}$ The main disadvantage of low speed flywheels is the limited energy storage and of high speed flywheels is the cost. 14

\subsection{Capacitor energy storage}

The most direct and literal way of storing electrical energy is with a capacitor. ${ }^{12}$ These systems would be more suitable for applications with many charge and discharge cycles and discharge times around 10 seconds. ${ }^{13}$ Capacitors can be charged substantially faster than conventional batteries and cycled tens of thousands of times with a high efficiency. ${ }^{12}$ However, the main problem presented by conventional capacitors is the low energy density. ${ }^{12}$

\subsection{Superconducting magnetic energy storage}

Superconducting magnetic energy storage (SMES) is the only known technology to store electrical energy directly into electric. ${ }^{12}$ Superconducting magnetic energy storage systems are most commonly used for power quality improvement and it has installed capacities of up to about $10 \mathrm{MW} .{ }^{13}$ SMES exhibits a very high energy storage efficiency (typically $>\sim 97 \%$ ) and a rapid response (within a few milliseconds) when compared with other energy storage systems, but only for short periods of time. ${ }^{12}$ They are used in a number of technical applications where very high magnetic fields are required, such as in medical devices. ${ }^{13}$ The major problems confronting the implementation of SMES units are the high cost and environmental issues associated with strong magnetic field. ${ }^{12}$

\subsection{Flow battery energy storage}

Flow batteries are electrochemical devices which store energy in electrolytes which contain dissolved electro active species. Flow batteries are highly flexible in terms of energy, as the energy is proportional to the amount of electrolyte utilised. ${ }^{14}$ Flow batteries can release energy continuously at a high rate of discharge for up to 10 hours, they need low maintenance so, and the storage time is over a long period. ${ }^{12,1}$ Flow batteries have different types in itself. These are vanadium redox battery (VRB), polysulphide Bromide Batteries (PSB) and zinc bromine battery ( $\mathrm{ZnBr})$. VBR appears to be better than PSB and $\mathrm{ZnB}$ because of its capacity and life cycleperformance. ${ }^{1}$

\subsection{Hydrogen energy storage}

Hydrogen is seen as the most promising alternative to conventional energy carriers. ${ }^{15}$ Hydrogen is one of the cleanest the most efficient and the lightest fuel; however, it is not found naturally and must be produced from the primary energy sources. ${ }^{1}$ The advantages of hydrogen are high energy density, modular construction, applicability to a wider range of sizes and power outputs and environmentally friendly operating principles. The disadvantages are its high costs and low efficiency. ${ }^{15}$

\section{The Proposed Methodology}

In this paper a hybrid MCDM methodology based on type-2 fuzzy sets is proposed to evaluate electrical energy storage alternatives. This hybrid methodology consists of type-2 fuzzy AHP and type-2 fuzzy TOPSIS methodologies as shown in Figure 1. Based on the studies in literature and decision makers' opinions, the alternatives are determined. Then, main and sub-criteria that affect these alternatives are identified. By using type-2 fuzzy AHP, the sub-criteria weights are determined. These obtained weights are used in the type-2 fuzzy TOPSIS and the best electrical energy storage alternatives are determined. Figure 1 explains the framework of the proposed methodology. 


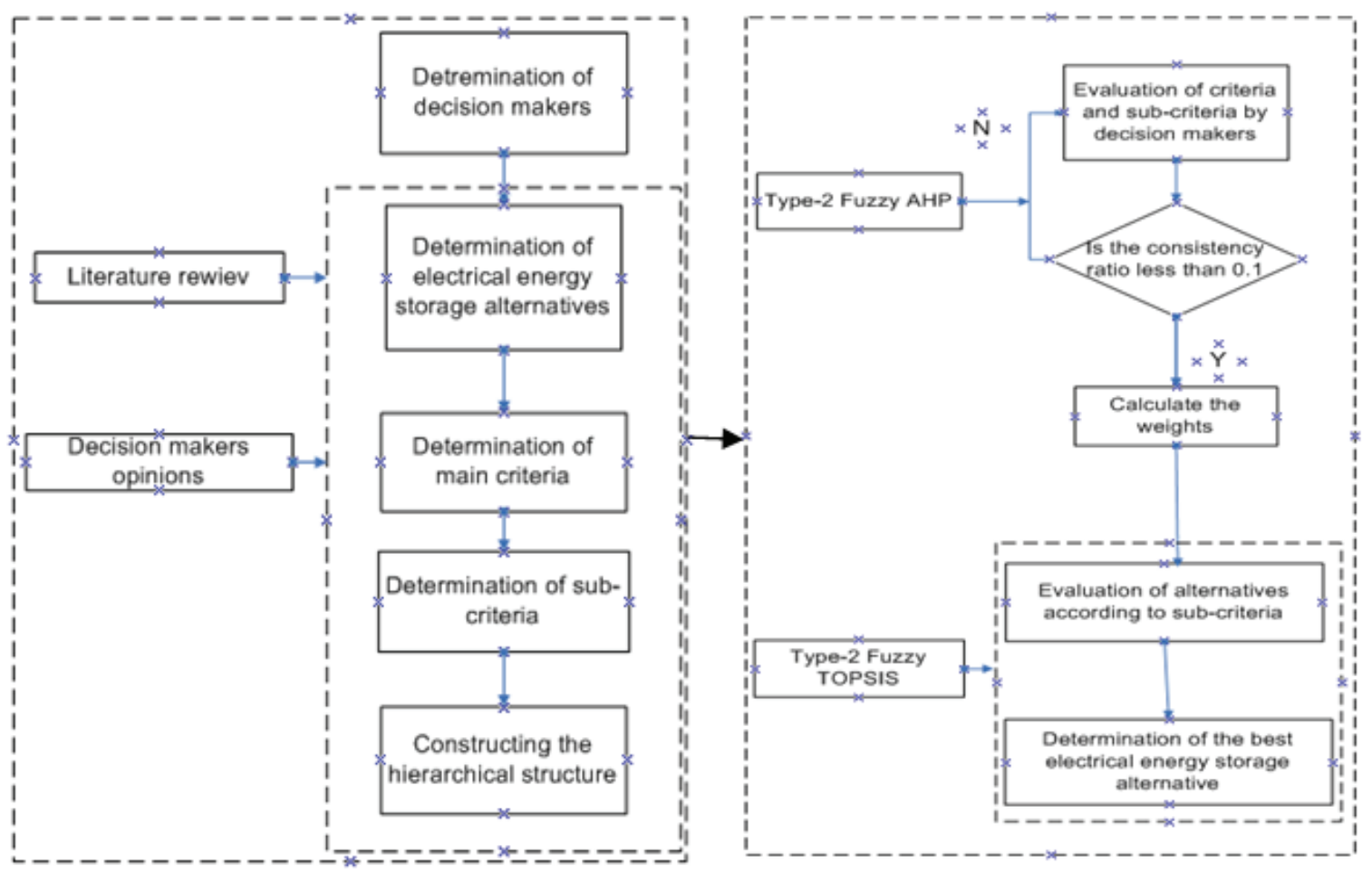

Fig. 1. The flowchart of the proposed methodology based on type-2 fuzzy sets

\subsection{Type-2 fuzzy sets}

Type-2 fuzzy sets are an extension of an ordinary fuzzy set. Its membership functions are type-1 fuzzy sets. ${ }^{10}$ Type- 1 fuzzy sets are not able to directly model uncertainties because their membership functions are totally crisp. On the other hand, type-2 fuzzy sets can model uncertainties because their membership functions are fuzzy. ${ }^{17}$ Type-2 fuzzy sets can be used to convey the uncertainties in membership functions of type-1 fuzzy sets, due to the dependence of the membership functions on available linguistic and numerical information. ${ }^{10}$ In this section the general definitions of type-2 fuzzy sets are explained as follows: ${ }^{18,19}$

Definition 1: A type 2 fuzzy set $\tilde{\tilde{A}}$ in the universe of discourse $X$ can be represented by a type -2 membership function $\mu_{\tilde{\tilde{A}}}$ shown as follows:

$\tilde{\tilde{A}}=\left\{\left((x, u), \mu_{\tilde{\tilde{A}}}(x, u)\right) \| \forall x \in X, \forall u \in J_{x} \subseteq[0,1], 0 \leq \mu_{\tilde{\tilde{A}}}(x, u) \leq 1\right\}$

where $J_{x}$ denotes an interval in $[0,1]$. Furthermore, the type-2 fuzzy set $\tilde{\tilde{A}}$ also can be represented as follows :

$$
\tilde{\tilde{A}}=\int_{x \in X} \int_{u \in J_{x}} \mu_{\tilde{A}}=(x, u) /(x, u)
$$

where $J_{x} \subseteq[0,1]$ and $\iint$ denotes union overall admissible $\mathrm{x}$ and $\mathrm{u}$.

Definition 2 : Let $\tilde{\tilde{A}}$ be type-2 fuzzy set in the universe of discourse $\mathrm{X}$ represented by the type- 2 membership function $\mu_{\tilde{\tilde{A}}}$. If all $\mu_{\tilde{\tilde{A}}}(\mathrm{x}, \mathrm{u})=1$, then $\tilde{\tilde{A}}$ is called an interval type-2 fuzzy set. An interval type-2 fuzzy set $\tilde{\tilde{A}}$ can be regarded as a special case of a type-2 fuzzy set, represented as follows:

$\tilde{\tilde{A}}=\int_{x \in X} \int_{u \in J_{x}} 1 /(x, u)$,

where $J_{x} \subseteq[0,1]$.

Definition 3: The upper membership function and the lower membership function of an interval type-2 fuzzy set are type-1 membership functions, respectively.

A trapezoidal interval type-2 fuzzy set: ${ }^{20,19}$ $\tilde{\tilde{A}}_{i}=\left(\tilde{A_{i}^{U}}, \tilde{A}_{i}^{L}\right)=\left(\left(a_{i 1}^{U}, a_{i 2}^{U}, a_{i 3}^{U}, a_{i 4}^{U} ; H_{1}\left(\tilde{A}_{i}^{U}\right), H_{2}\left(\tilde{A}_{i}^{U}\right)\right),\left(a_{i 1}^{L}, a_{i 2}^{L}, a_{i 3}^{L}, a_{i 4}^{L} ; H_{1}\left(\tilde{A}_{i}^{L}\right), H_{2}\left(\tilde{A}_{i}^{L}\right)\right)\right)$

where $\quad \tilde{A}_{i}^{u}$ and $\quad \tilde{A}_{i}^{L}$ are type 1 fuzzy sets. $a_{i 1}^{U}, a_{i 2}^{U}, a_{i 3}^{U}, a_{i 4}^{U}, a_{i 1}^{L}, a_{i 2}^{L}, a_{i 3}^{L}$ and $a_{i 4}^{L}$ are the reference points of the interval type-2 fuzzy set $\stackrel{\sim}{\tilde{A}_{i}}, H_{j}\left(\tilde{A}_{i}^{U}\right)$ denotes the membership value of the element $a_{i(j+1)}^{U}$ in the upper trapezoidal membership function ${ }_{A_{i}}^{U}, 1 \leq j \leq 2, H_{j}\left(A_{i}^{L}\right)$ denotes the membership value of the element $a_{i(j+1)}^{L}$ in the lower trapezoidal membership 
function

$$
\begin{aligned}
& \left.\tilde{A}_{i}^{L}, 1 \leq j \leq 2, H_{1}\left(\tilde{A}_{i}^{U}\right) \in[0,1], H_{2}\left(\tilde{A}_{i}^{U}\right) \in[0,1], H_{1} \tilde{A}_{i}^{L}\right) \in[0,1], H_{2}\left(\tilde{A}_{i}^{L}\right) \in[0,1] \\
& , 1 \leq i \leq n .
\end{aligned}
$$

\subsection{Type-2 fuzzy $A H P$}

In this paper, the fuzzy AHP methodology is considered with type-2 fuzzy set theory to determine the weights of sub-criteria. In this sub-section the steps of fuzzy AHP based on interval type-2 fuzzy sets are detailed $^{22,24,29}$.

Step 1: Fuzzy decision matrices for each criterion and alternative are created as shown below:.

$$
\tilde{\tilde{A}}=\left[\begin{array}{cccc} 
& \tilde{\sim} & & \sim \\
1 & \tilde{a_{12}} & \ldots & \tilde{a}_{1 m} \\
\tilde{\tilde{a}} & & & \tilde{\sim} \\
a_{21} & 1 & \ldots & \tilde{a} a_{2 m} \\
& & 1 & \\
\tilde{\sim} & \tilde{\sim} & & \\
a_{n 1} & a_{n 2} & \ldots & 1
\end{array}\right] \text { where } \tilde{\tilde{a}}_{j i}=\frac{1}{\tilde{\tilde{a}}_{i j}}
$$

where

$\tilde{\tilde{a}}=\left[\left(a_{11}^{U}, a_{12}^{U}, a_{13}^{U}, a_{14}^{U} ; H_{1}\left(a^{U}\right), H_{2}\left(a^{U}\right)\right]\right.$,

$\left.\left(a_{11}^{L}, a_{12}^{L}, a_{13}^{L}, a_{14}^{L} ; H_{1}\left(a^{L}\right), H_{2}\left(a^{L}\right)\right)\right]$

Therefore,

$\frac{1}{\tilde{\tilde{a}}}=\left[\left(\frac{1}{a_{14}^{U}}, \frac{1}{a_{13}^{U}}, \frac{1}{a_{12}^{U}}, \frac{1}{a_{11}^{U}} ; H_{1}\left(a_{12}^{U}\right), H_{2}\left(a_{13}^{U}\right)\right),\left(\frac{1}{a_{14}^{L}}, \frac{1}{a_{13}^{L}}, \frac{1}{a_{12}^{L}}, \frac{1}{a_{11}^{L}} ; H_{1}\left(a_{12}^{L}\right), H_{2}\left(a_{13}^{L}\right)\right)\right]$

Step 2: The consistency of the comparison matrices are checked. It should be less than 0.1 .

Step 3: Fuzzy geometric mean for each criterion are obtained based on Eq. (9).

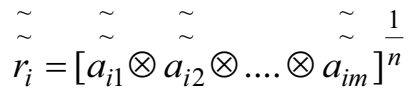

where,

$\left(\tilde{\tilde{a}}_{i j}\right)^{\frac{1}{n}}=\left[\left(\left(a_{i 1}^{U}\right)^{\frac{1}{n}},\left(a_{i 2}^{U}\right)^{\frac{1}{n}},\left(a_{i 3}^{U}\right)^{\frac{1}{n}},\left(a_{i 4}^{U}\right)^{\frac{1}{n}} ; H_{1}\left(a_{12}^{U}\right), H_{2}\left(a_{13}^{U}\right)\right),\left(\left(a_{i 1}^{L}\right)^{\frac{1}{n}},\left(a_{i 2}^{L}\right)^{\frac{1}{n}},\left(a_{i 3}^{L}\right)^{\frac{1}{n}},\left(a_{i 4}^{L}\right)^{\frac{1}{n}} ; H_{1}\left(a_{12}^{L}\right), H_{2}\left(a_{13}^{L}\right)\right)\right]$

Step 4: The fuzzy weights of criteria are determined by using Eq. (11).

$W_{i}=\tilde{\tilde{r}}_{i} \otimes\left[\tilde{\tilde{r}}_{1}+\tilde{\tilde{r}}_{2}+\ldots+\tilde{\tilde{r}}_{n}\right]^{-1}$

\subsection{Type-2 fuzzy TOPSIS}

In this sub-section, the steps of fuzzy TOPSIS methodology based on interval type-2 fuzzy sets are explained $^{19}: X$ is a set of alternatives where $X=\left\{x_{1}\right.$, $\left.x_{2}, \ldots \ldots \ldots, x_{n}\right\}$ and $F$ is a set of attributes where $F=\left\{f_{1}\right.$, $\left.f_{2}, \ldots \ldots, f_{m}\right\}$. There are $k$ decision makers $D_{1}, D_{2}, \ldots$, $\mathrm{D}_{\mathrm{k}}$. The set $\mathrm{F}$ of attributes can be divided into two sets $F_{1}$ and $F_{2}$, where $F_{1}$ denotes the set of benefit attributes, $F_{2}$ denotes the set of cost attributes, $\mathrm{F}_{1} \cap \mathrm{F}_{2}=\varphi$ and $\mathrm{F}_{1} \mathrm{UF}_{2}=\mathrm{F}$.

Step 1: The decision matrix $Y_{p}$ of the $p^{\text {th }}$ decisionmaker and the average decision matrix $\bar{Y}$ is constructed.

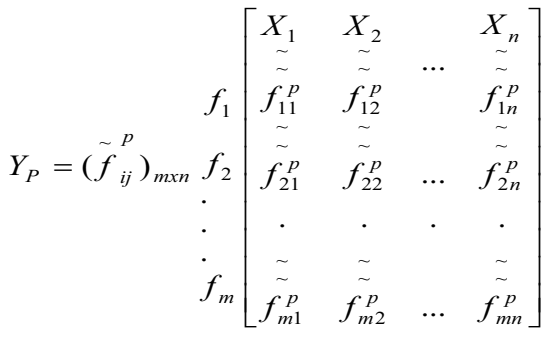

$$
\bar{Y}=\left(\tilde{f}_{i j}\right)_{m x n}
$$

where $\tilde{\tilde{f}}_{i j}=\left(\frac{\tilde{\tilde{f}}_{i j}^{1} \oplus \tilde{\tilde{f}}_{i j}^{2} \oplus \ldots \oplus \tilde{\tilde{f}}_{i j}^{k}}{k}\right), \tilde{\tilde{f}}_{i j}$ is an interval

type- 2 fuzzy set, $1 \leq \mathrm{i} \leq \mathrm{m}, 1 \leq \mathrm{j} \leq \mathrm{n}, 1 \leq \mathrm{p} \leq \mathrm{k}$, and $\mathrm{k}$

denotes the number of decision makers.

Step 2: The weighting matrix $\mathrm{W}_{\mathrm{p}}$ of the attributes of the $\mathrm{p}$ th decision -maker and the average weighting matrix $\bar{W}$, respectively as follows:

$$
\underset{W_{p}}{\stackrel{\sim}{\sim}}\left(W_{i}^{p}\right)_{l x m}=\left[\begin{array}{cccc}
f_{1} & f_{2} & & \tilde{f}_{m} \\
\underset{\sim}{\sim} & \tilde{\sim} & & \tilde{\sim} W_{1}^{p} \\
W_{2}^{p} & \ldots & W_{m}^{p} \\
& & &
\end{array}\right]
$$


$\tilde{\tilde{w}}_{i}=\left(\frac{\tilde{\tilde{w}}_{i}^{1} \oplus \tilde{\tilde{w}}_{i}^{2} \oplus \ldots \oplus \tilde{\tilde{w}}_{i}^{k}}{k}\right)$

$\tilde{w}_{i}$ is an interval type-2 fuzzy set, $1 \leq i \leq m$, $1 \leq p \leq k$ and $\mathrm{k}$ denotes the number of decision makers.

Step 3: The weighted decision matrix $\bar{Y}_{w}$ is constructed.

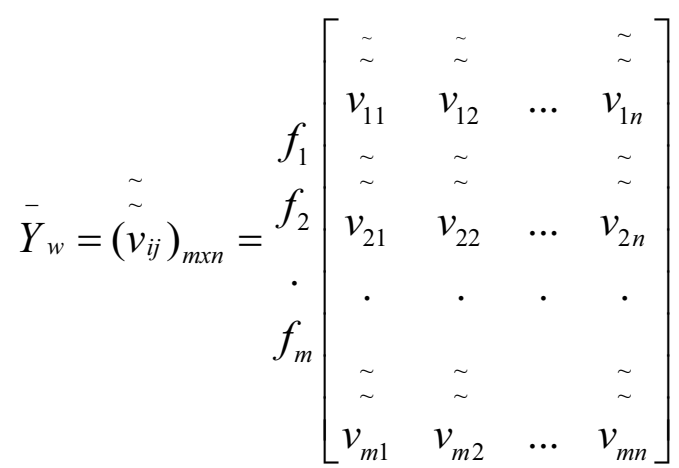

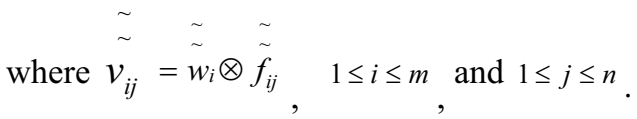

Step 4: The ranking value $\operatorname{Rank}\left(\tilde{\tilde{v}}_{i j}\right)$ of the interval type-2 fuzzy set $\left(\tilde{\tilde{v}}_{i j}\right)$, where $1 \leq j \leq n$ is calculated based on Eq. ( 16 ). Then the ranking weighted decision matrix $\bar{Y}_{w}$ is constructed.

The concept of ranking values of trapezoidal interval type-2 fuzzy sets are presented by( 20,19$)$. The ranking value $\operatorname{Rank}\left(\tilde{\tilde{A}}_{i}\right)$ of the trapezoidal interval type-2 fuzzy set $\tilde{\tilde{A}}_{i}$ is defined as follows ${ }^{19}$ :
Rank

$$
\begin{aligned}
& (\tilde{\tilde{A}})= \\
& M_{1}\left(\tilde{A}_{i}^{U}\right)+M_{1}\left(\tilde{A}_{i}^{L}\right)+M_{2}\left(\tilde{A}_{i}^{U}\right)+M_{2}\left(\tilde{A}_{i}^{L}\right)+M_{3}\left(\tilde{A}_{i}^{U}\right)+M_{3}\left(A_{i}^{L}\right)- \\
& \frac{1}{4}\left(S_{1}\left(\tilde{A}_{i}^{U}\right)+S_{1}\left(\tilde{A}_{i}^{L}\right)+S_{2}\left(\tilde{A}_{i}^{U}\right)+S_{2}\left(\tilde{A}_{i}^{L}\right)+S_{3}\left(\tilde{A_{i}^{U}}\right)+S_{3}\left(\tilde{A}_{i}^{L}\right)+S_{4}\left(\tilde{A}_{i}^{U}\right)+S_{4}\left(\tilde{A}_{i}^{L}\right)\right) \\
& +H_{1}\left(\tilde{A}_{i}^{U}\right)+H_{1}\left(\tilde{A}_{i}^{L}\right)+H_{2}\left(\tilde{A_{i}^{U}}\right)+H_{2}\left(\tilde{A}_{i}^{L}\right)
\end{aligned}
$$

where $M_{p}\left(\tilde{A_{i}^{j}}\right)$ denotes the average of the elements

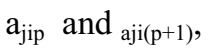

$M_{p}\left(\tilde{A_{i}^{j}}\right)=\left(a_{i p}^{j}+a_{i(p+1)}^{j}\right) / 2,1 \leq p \leq 3, S_{q}\left(\tilde{A_{i}^{j}}\right)$

denotes the standard deviation of the elements $\mathrm{a}_{\mathrm{ji}}{ }^{\mathrm{p}}$ and $\mathrm{a}_{\mathrm{ji}}^{\left(\mathrm{p}^{\mathrm{p}}+1\right)}$,

$S_{q}\left(\tilde{A_{i}^{j}}\right)=\sqrt{\frac{1}{2} \sum_{k-q}^{q+1}\left(a_{i k}^{j}-\frac{1}{2} \sum_{k 0 q}^{q+1} a_{i k}^{j}\right)^{2}}$

$1 \leq q \leq 3, S_{4}\left(\tilde{A_{i}^{j}}\right)$ denotes the standard deviation of the elements $\mathrm{a}_{\mathrm{ji}}{ }^{1}, \mathrm{a}_{\mathrm{ji}}{ }^{2}, \mathrm{a}_{\mathrm{ji}}{ }^{3}, \ldots$,

$S_{4}\left(\tilde{A_{i}^{j}}\right)=\sqrt{\frac{1}{4} \sum_{k=1}^{4}\left(a_{i k}^{j}-\frac{1}{4} \sum_{k=1}^{4} a_{i k}^{j}\right)^{2}}, H_{p}\left(\tilde{A_{j}^{i}}\right)$

denotes the membership value of the element aji $(\mathrm{p}+1)$ in the trapezoidal membership function. $A_{i}^{j}, 1 \leq p \leq 2, j \in\{U, L\}$, and $1 \leq \mathrm{i} \leq \mathrm{n}$.

$$
\overline{Y_{w}^{*}}=\left(\operatorname{Rank}\left(\tilde{\tilde{V}_{i j}}\right)\right)_{m \times n}, \quad \text { where } 1 \leq \mathrm{i} \leq \mathrm{m} \text { and } 1 \leq \mathrm{j} \leq \mathrm{n}
$$

Step 5: The positive ideal solution

$\mathrm{x}^{+}=\left(\mathrm{v}_{1}^{+}, \mathrm{v}_{2}^{+}, \ldots, \mathrm{v}_{\mathrm{m}}^{+}\right)$and the negative ideal solution $\mathrm{x}^{-}=\left(\mathrm{v}_{1}^{-}, \mathrm{v}_{2}^{-}, \ldots, \mathrm{v}_{\mathrm{m}}^{-}\right)$are determined. Where 


$$
v_{i}^{+}= \begin{cases}\max _{1 \leq j \leq n}\left\{\operatorname{Rank}\left(\tilde{v_{i j}}\right)\right\}, & \text { if } \mathrm{f}_{\mathrm{i}} \in \mathrm{F}_{1} \\ \min _{1 \leq j \leq n}\left\{\operatorname{Rank}\left(\tilde{v} \frac{\tilde{v}}{i j}\right)\right\}, & \text { if } \mathrm{f}_{\mathrm{i}} \in \mathrm{F}_{2}\end{cases}
$$

and

$$
v_{i}^{-}= \begin{cases}\min _{1 \leq j \leq n}\left\{\operatorname{Rank}\left(\tilde{v_{i j}}\right)\right\}, & \text { if } \mathrm{f}_{\mathrm{i}} \in \mathrm{F}_{1} \\ \max _{1 \leq j \leq n}\left\{\operatorname{Rank}\left(\tilde{v_{i j}}\right)\right\}, & \text { if } \mathrm{f}_{\mathrm{i}} \in \mathrm{F}_{2}\end{cases}
$$

where $F_{1}$ denotes the set of benefit attributes, $F_{2}$

denotes the set of cost attributes and $1 \leq \mathrm{i} \leq \mathrm{m}$.

Step 6: The distance $d^{+}\left(x_{j}\right)$ between each alternative $x_{j}$ and the positive ideal solution $\mathrm{x}^{+}$is calculated, shown as follows:

$$
d^{+}\left(x_{j}\right)=\sqrt{\sum_{i=1}^{m}\left(\underset{\tilde{\tilde{v}}}{\tilde{R} \operatorname{Rank}\left(v_{i j}\right)-v_{i}^{+}}\right)^{2}}
$$

where $1 \leq \mathrm{j} \leq \mathrm{n}$. The distance $\mathrm{d}^{-}\left(\mathrm{x}_{\mathrm{j}}\right)$ between each alternative $x_{j}$ and the negative ideal solution $x^{-}$is calculated, shown as follows:

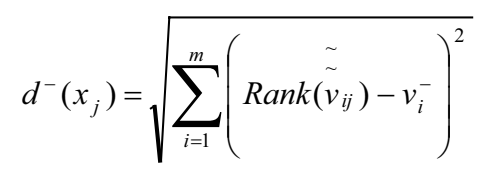

where $1 \leq \mathrm{j} \leq \mathrm{n}$.

Step 7: The relative degree of closeness $C\left(x_{j}\right)$ of $x_{j}$ with respect to the positive ideal solution $\mathrm{x}^{+}$is calculated, shown as follows:

$C\left(x_{j}\right)=\frac{d^{-}\left(x_{j}\right)}{d^{+}\left(x_{j}\right)+d^{-}\left(x_{j}\right)}$

where $1 \leq \mathrm{j} \leq \mathrm{n}$.

Step 8: The values of $C\left(x_{j}\right)$ in a descending sequence is sorted, where $1 \leq j \leq n$. The larger the value of $C\left(x_{j}\right)$, the higher the preference of the alternative $\mathrm{x}_{\mathrm{j}}$, where $1 \leq \mathrm{j} \leq \mathrm{n}$.

\section{Application of the Proposed Methodology}

In this paper, a new hybrid methodology based on type 2 fuzzy AHP and TOPSIS methodologies is proposed. The aim of the proposed methodology is to determine on the best electrical energy storage technology among alternatives. The proposed methodology consists of two main steps: fuzzy AHP and fuzzy TOPSIS. Fuzzy AHP based on type-2 fuzzy sets provides to determine the weights of criteria and sub-criteria that are used to determine the best alternative. In the second stage the fuzzy TOPSIS methodology based on type-2 fuzzy sets evaluate the alternatives according to these criteria. There are many different factors that affect the most suitable electrical energy storage technology. The criteria and alternatives are identified by the decision makers and from the literature. To evaluate the criteria and alternatives three decision makers that are experts in energy field are selected. Then the decision makers evaluate the main and sub- criteria by using a linguistic scale shown in Table 1. The weights of subcriteria are determined with type-2 fuzzy AHP and using these weights total points of each alternative are determined and the best electrical energy storage alternative is chosen. 
Table 1. Linguistic scales

\begin{tabular}{|l|l|}
\hline \multicolumn{1}{|c|}{ Linguistic Terms } & \multicolumn{1}{|c|}{ Type-2 Fuzzy Numbers } \\
\hline Equal $(\mathrm{Eq})$ & {$[(1,1,1,1 ; 1,1),(1,1,1,1 ; 0.90,0.90)]$} \\
\hline More Important $(\mathrm{Mo})$ & {$[(1,2,4,5 ; 1,1),(1.2,2.2,3.8,4.8 ; 0.90,0.90)]$} \\
\hline Very Important $(\mathrm{Vr})$ & {$[(3,4,6,7 ; 1,1),(3.2,4.2,5.8,6.8 ; 0.90,0.90)]$} \\
\hline Very Strong Important $(\mathrm{Vs})$ & {$[(5,6,8,9 ; 1,1),(5.2,6.2,7.8,8.8 ; 0.90,0.90)]$} \\
\hline Absolutely Important $(\mathrm{Ab})$ & {$[(7,8,9,9 ; 1,1),(7.2,8.2,8.8,8.8 ; 0.90,0.90)]$} \\
\hline
\end{tabular}

There are different criteria that have critical influence on the selection process. The alternatives and criteria are determined by the decision makers and from the studies in literature. ${ }^{1,3,12,14,15,21}$ There are three decision makers. One of them is an academician his research interests are multi-criteria decision making and energy systems. Two decision makers are managers at the energy companies.

The alternative technologies are determined as follow:

-Compressed Air Energy Storage

- Pumped Hydro Energy Storage

- Battery Energy Storage

-Flywheels

-Capacitors

- Superconducting Magnetic Energy Storage

The main criteria are grouped under four categories.

The four main criteria have 16 sub-criteria and a subcriterion has its own sub-criteria. These are:

$\mathrm{C}_{1}$ :Political and Social

- $\quad \mathrm{C}_{11}$ : Social acceptance

- $\quad \mathrm{C}_{12}$ : Political acceptance

$\mathrm{C}_{2}$ : Environmental impacts

- $\mathrm{C}_{21}$ : Green land impacts

- $\quad \mathrm{C}_{22}$ : Ecological impacts

- $\mathrm{C}_{23}$ : Toxic impacts

- $\mathrm{C}_{24}$ : Human health impacts

$\mathrm{C}_{3}$ : Cost

- $\mathrm{C}_{31}$ : Capital cost

- $\mathrm{C}_{32}$ : Storage cost

- $\quad \mathrm{C}_{33}$ : Operation and Maintenance cost (O\&M)

- $\quad \mathrm{C}_{34}$ : Energy cost

$\mathrm{C}_{4}$ : Technical

- $\quad \mathrm{C}_{41}$ : Storage capacity

- $\mathrm{C}_{42}$ : Density

- $\mathrm{C}_{43}$ : Efficiency
- $\mathrm{C}_{44}$ : Discharge ratio

- $\mathrm{C}_{45}$ :Maturity

- $\mathrm{C}_{46}:$ Lifetime

- $\mathrm{C}_{461}$ : Cycle number

○ $\mathrm{C}_{462}$ : Reliability

Figure 2 shows the hierarchical structure for selection of the electrical energy storage alternative problem. The decision makers evaluate every sub-criteria according to the linguistic scale that is shown in Table 1. Table 2 shows an example for the evaluations of three decision makers related with sub-criteria of "Cost".

Table 2. An example for the evaluations of three decision makers related with sub-criteria of "Cost"

\begin{tabular}{|c|c|c|c|c|}
\hline \multicolumn{5}{|c|}{ DM1 } \\
\hline & Capital & Storage & O\&M & Energy \\
\hline Capital & & $\mathrm{Vr}$ & Mo & Mo \\
\hline Storage & & & 1/Mo & 1/Mo \\
\hline O\&M & & & & $\mathrm{Vr}$ \\
\hline Energy & & & & \\
\hline \multicolumn{5}{|c|}{$\overline{\mathrm{DM} 2}$} \\
\hline & Capital & Storage & O\&M & Energy \\
\hline Capital & & $\mathrm{Vr}$ & Mo & Mo \\
\hline Storage & & & 1/Mo & 1/Mo \\
\hline O\&M & & & & Mo \\
\hline Energy & & & & \\
\hline \multicolumn{5}{|c|}{ DM3 } \\
\hline & Capital & Storage & O\&M & Energy \\
\hline Capital & & $\mathrm{Vr}$ & Mo & Mo \\
\hline Storage & & & $1 / \mathrm{Mo}$ & 1/Mo \\
\hline O\&M & & & & Mo \\
\hline Energy & & & & \\
\hline
\end{tabular}




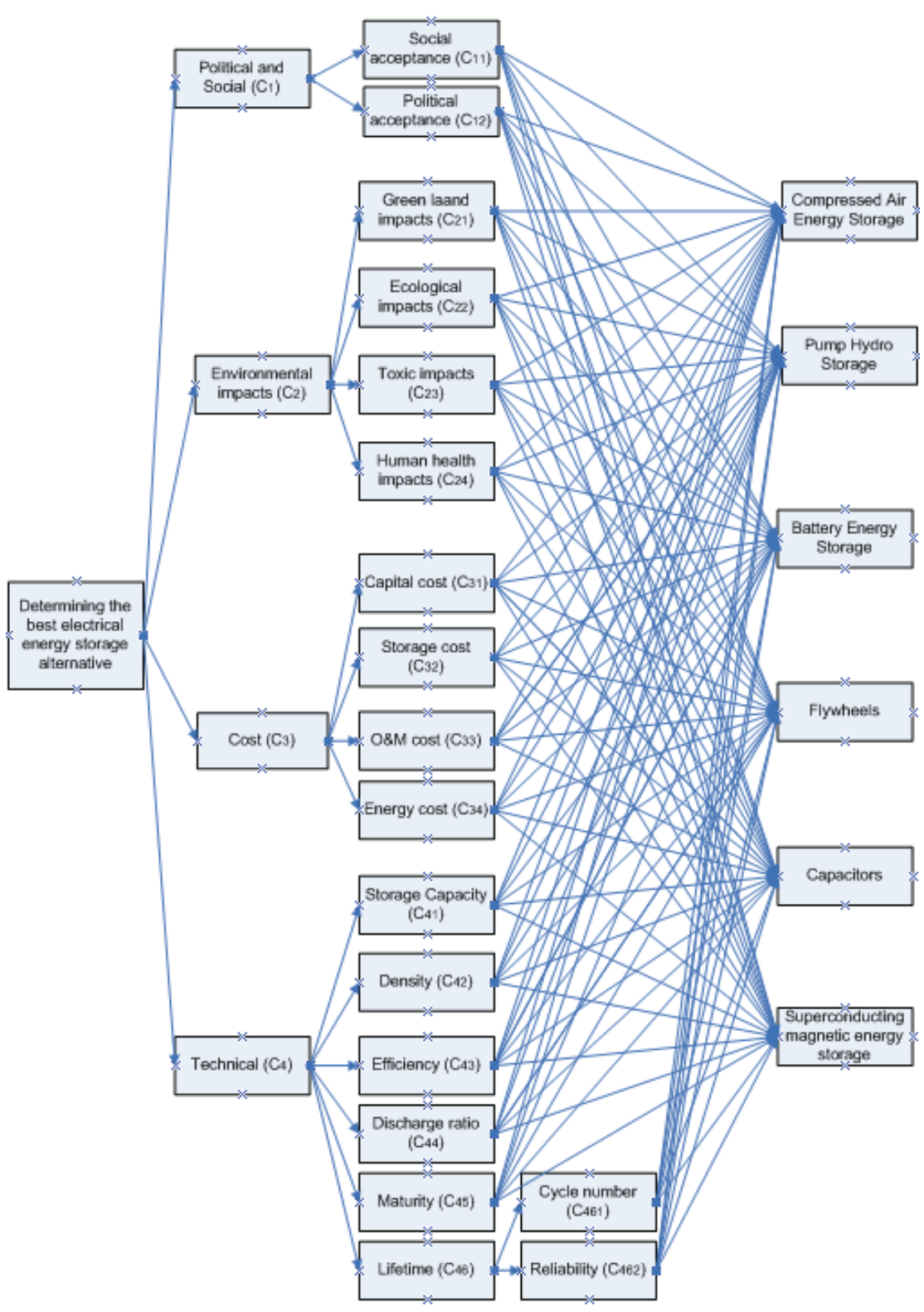

Fig. 2. The hierarchical structure of the problem

While type-2 fuzzy sets enable more flexible and sensitive analysis, type- 2 fuzzy AHP is preferred to obtain the weights of criteria. Table 3 shows the weights of each sub-criteria as type-2 fuzzy numbers.
The evaluations of decision makers have been checked with respect to consistency and the ratio of 0.1 is confirmed.

Table 3 Type-2 fuzzy weights of sub-criteria

\begin{tabular}{|l|l|}
\hline \multicolumn{1}{|c|}{ Sub-criteria } & \multicolumn{1}{|c|}{ Type-2 fuzzy weights } \\
\hline Lifetime & {$[(0.004,0.011,0.066,0.24 ; 1,1),(0.005,0.013,0.054,0.175 ; 0.9,0.9)]$} \\
\hline \multicolumn{1}{|c|}{ Cycle number } & {$[(0.002,0.007,0.068,0.301 ; 1,1),(0.003,0.009,0.053,0.21 ; 0.9,0.9)]$} \\
\hline \multicolumn{1}{|c|}{ Reliability } & {$[(0,0.002,0.014,0.066 ; 1,1),(0.001,0.002,0.011,0.045 ; 0.9,0.9)]$} \\
\hline Maturity & {$[(0.003,0.008,0.048,0.185 ; 1,1),(0.003,0.009,0.038,0.132 ; 0.9,0.9)]$} \\
\hline & {$[(0.002,0.005,0.028,0.108 ; 1,1),(0.003,0.006,0.024,0.084 ; 0.9,0.9)]$} \\
\hline Efficiency & {$[(0.002,0.004,0.022,0.088 ; 1,1),(0.002,0.005,0.018,0.062 ; 0.9,0.9)]$} \\
\hline Density & {$[(0.002,0.003,0.019,0.083 ; 1,1),(0.002,0.004,0.015,0.057 ; 0.9,0.9)]$} \\
\hline
\end{tabular}


A hybrid MCDM methodology based on type-2 fuzzy sets

\begin{tabular}{|l|l|}
\hline \multicolumn{1}{|c|}{ Sub-criteria } & \multicolumn{1}{|c|}{ Type-2 fuzzy weights } \\
\hline Storage Capacity & {$[(0.005,0.017,0.104,0.35 ; 1,1),(0.007,0.02,0.085,0.261 ; 0.9,0.9)]$} \\
\hline Energy cost & {$[(0.009,0.028,0.187,0.639 ; 1,1),(0.012,0.039,0.175,0.494 ; 0.9,0.9)]$} \\
\hline O\&M cost & {$[(0.014,0.052,0.345,1.076 ; 1,1),(0.02,0.063,0.279,0.818 ; 0.9,0.9)]$} \\
\hline Storage cost & {$[(0.005,0.016,0.099,0.356 ; 1,1),(0.007,0.019,0.079,0.259 ; 0.9,0.9)]$} \\
\hline Capital cost & {$[(0.026,0.099,0.622,1.702 ; 1,1),(0.036,0.119,0.509,1.342 ; 0,9,0,9)]$} \\
\hline Human health impacts & {$[(0.015,0.054,0.345,1.044 ; 1,1),(0.029,0.074,0.282,0.505 ; 0.9,0.9)]$} \\
\hline Toxic impacts & {$[(0.003,0.009,0.055,0.218 ; 1,1),(0.005,0.01,0.041,0.144 ; 0.9,0.9)]$} \\
\hline Ecological impacts & {$[(0.008,0.024,0.147,0.491 ; 1,1),(0.012,0.028,0.113,0.341 ; 0.9,0.9)]$} \\
\hline Green land impacts & {$[(0.007,0.02,0.124,0.429 ; 1,1),(0.01,0.024,0.094,0.294 ; 0.9,0.9)]$} \\
\hline Political acceptance & {$[(0.008,0.015,0.064,0.23 ; 1,1),(0.009,0.017,0.053,0.166 ; 0.9,0.9)]$} \\
\hline Social acceptance & {$[(0.018,0.042,0.181,0.515 ; 1,1),(0.022,0.048,0.153,0.399 ; 0.9,0.9)]$} \\
\hline
\end{tabular}

The obtained fuzzy weights are used in the type-2 fuzzy TOPSIS method to get the final ranking of the best electrical energy storage technology. The decision makers evaluate the alternatives according to sub- criteria using the same linguistic scale in Table 1. Table 4 shows the linguistic evaluation of alternatives according to social acceptance sub-criteria.

Table 4. Linguistic evaluation of alternatives according to social acceptance

\begin{tabular}{|l|l|l|l|l|}
\hline \multicolumn{1}{|c|}{ Sub-criteria } & \multicolumn{1}{|c|}{ Alternatives } & DM1 & DM2 & DM3 \\
\hline \multirow{5}{*}{ Social acceptance } & Compressed Air Energy Storage & $\mathrm{Vr}$ & $\mathrm{Vr}$ & $\mathrm{Mo}$ \\
\cline { 2 - 6 } & Pumped Hydro Energy Storage & $\mathrm{Mo}$ & $\mathrm{Mo}$ & $\mathrm{Vr}$ \\
\cline { 2 - 6 } & Battery Energy Storage & $\mathrm{Eq}$ & $1 / \mathrm{Vr}$ & $1 / \mathrm{Mo}$ \\
\cline { 2 - 6 } & Flywheels & $\mathrm{Eq}$ & $1 / \mathrm{Mo}$ & $1 / \mathrm{Mo}$ \\
\cline { 2 - 5 } & Capacitors & $1 / \mathrm{Mo}$ & $1 / \mathrm{Vr}$ & $1 / \mathrm{Mo}$ \\
\cline { 2 - 5 } & Superconducting magnetic energy storage & $1 / \mathrm{Vr}$ & $1 / \mathrm{Vr}$ & $1 / \mathrm{Vr}$ \\
\hline
\end{tabular}

The arithmetic mean of three decision makers' evaluation is calculated and the average results are obtained. Table 5 shows the average decision matrix for the social acceptance sub-criteria. These results are multiplied with the weights that are determined by type-2 fuzzy AHP and the weighted matrix is created. Then the ranking values are obtained. Positive and negative ideal solutions are obtained. Table 6 indicates the positive and negative ideal solutions of alternatives. Lastly the final results of alternatives are calculated. Table 7 shows the final rankings of alternatives according to type- 2 fuzzy TOPSIS method.

Table 5. Average decision matrix for the social acceptance sub-criteria

\begin{tabular}{|l|l|}
\hline \multicolumn{1}{|c|}{ Alternatives } & \multicolumn{1}{c|}{ Type-2 fuzzy numbers } \\
\hline Compressed Air Energy Storage & {$[(2.3,3.33,5.33,6.33 ; 1,1),(2.53,3.53,5.13,6.13 ; 0.9,0.9)]$} \\
\hline Pumped Hydro Energy Storage & {$[(1.6,2.67,4.67,5.67 ; 1,1),(1.87,2.87,4.47,5.47 ; 0.9,0.9)]$} \\
\hline Battery Energy Storage & {$[(0.4,0.47,0.58,0.78 ; 1,1),(0.45,0.48,0.56,0.72,0.9,0.9)]$} \\
\hline Flywheels & {$[(0.4,0.50,0.67,1.00 ; 1,1),(0.47,0.51,0.64,0.89,0.9,0.9)]$} \\
\hline Capacitors & {$[(0.18,0.22,0.42,0.78 ; 1,1),(0.19,0.23,0.38,0.66 ; 0.9,0.9)]$} \\
\hline Superconducting Magnetic energy storage & {$[(0.14,0.17,0.25,0.33 ; 1,1),(0.15,0.17,0.24,0.31 ; 0.9,0.9)]$} \\
\hline
\end{tabular}




\section{B. Ozkan et al.}

Table 6. Positive and negative ideal solutions of alternatives

\begin{tabular}{|l|c|c|}
\hline \multicolumn{1}{|c|}{ Alternatives } & $\left.\mathbf{( d}^{+}\right)$ & $\left.\mathbf{( d}^{-}\right)$ \\
\hline Compressed Air Energy Storage & 3.779 & 20.424 \\
\hline Pumped Hydro Energy Storage & 11.893 & 11.322 \\
\hline Battery Energy Storage & 16.480 & 4.090 \\
\hline Flywheels & 17.327 & 9.271 \\
\hline Capacitors & 14.155 & 8.570 \\
\hline Superconducting magnetic energy storage & 19.496 & 4.411 \\
\hline
\end{tabular}

Table 7. Final result of alternatives

\begin{tabular}{|l|c|}
\hline \multicolumn{1}{|c|}{ Alternatives } & Relative degree of closeness \\
\hline Compressed Air Energy Storage & 0.844 \\
\hline Pumped Hydro Energy Storage & 0.694 \\
\hline Battery Energy Storage & 0.199 \\
\hline Flywheels & 0.349 \\
\hline Capacitors & 0.377 \\
\hline Superconducting Magnetic Energy Storage & 0.185 \\
\hline
\end{tabular}

According to hybrid methodology based on type-2 fuzzy sets, the alternative "Compressed Air Energy Storage" technology is obtained as the best electrical energy storage technology. "Pumped Hydro Energy Storage" technology ranked second best alternative. Then the best alternatives are "Flywheels", "Capacitors" and "Battery Energy Storage" technologies respectively. And "Superconducting Magnetic Energy Storage" technology is ranked sixth best alternative.

\subsection{Sensitivity analysis}

In this sub-section a sensitivity analysis is conducted to show effects of criteria weights on ranking. For this aim, the weights of the sub-criteria "Capital cost" and "Human health impacts" are changed and their impacts on the final score of alternatives have been analyzed.. Table 8 shows the weights of "Capital cost" and "Human health impact" according to five scenarios.

Table 8. The weights of "Capital cost" and "Human health impacts" for sensitivity analysis

\begin{tabular}{|l|l|l|}
\hline & \multicolumn{1}{|c|}{ Sub-criteria } & \multicolumn{1}{c|}{ Weights } \\
\hline Actual situation & Capital cost & {$[(0.026,0.099,0.622,1.702 ; 1,1),(0.036,0.119,0.509,1.342 ; 0,9,0,9)]$} \\
& Human health impacts & {$[(0.015,0.054,0.345,1.044 ; 1,1),(0.029,0.074,0.282,0.505 ; 0.9,0.9)]$} \\
\hline Scenario 1 & Capital cost & {$[(0.052,0.2,1.24,3.4 ; 1,1),(0.072,0.24,1.08,2.68 ; 0.9,0.9)]$} \\
& Human health impacts & {$[(0.015,0.054,0.345,1.044 ; 1,1),(0.029,0.074,0.282,0.505 ; 0.9,0.9)]$} \\
\hline Scenario 2 & Capital cost & {$[(0.013,0.05,0.31,0.85 ; 1,1),(0.018,0.06,0.255,0.67 ; 0.9,0.9)]$} \\
& Human health impacts & {$[(0.015,0.054,0.345,1.044 ; 1,1),(0.029,0.074,0.282,0.505 ; 0.9,0.9)]$} \\
\hline Scenario 3 & Capital cost & {$[(0.026,0.099,0.622,1.702 ; 1,1),(0.036,0.119,0.509,1.342 ; 0,9,0,9)]$} \\
& Human health impacts & {$[(0.03,0.108,0.69,2.09),(0.058,0.148,0.56,1.01 ; 0.9,0.9)]$} \\
\hline Scenario 4 & Capital cost & {$[(0.026,0.099,0.622,1.702 ; 1,1),(0.036,0.119,0.509,1.342 ; 0,9,0,9)]$} \\
& Human health impacts & {$[(0.007,0.027,0.172,0.522 ; 1,1),(0.014,0.037,0.141,0.252$} \\
\hline Scenario 5 & Capital cost & {$[(0.052,0.2,1.24,3.4 ; 1,1),(0.072,0.24,1.08,2.68 ; 0.9,0.9)]$} \\
& Human health impacts & {$[(0.03,0.108,0.69,2.09),(0.058,0.148,0.56,1.01 ; 0.9,0.9)]$} \\
\hline
\end{tabular}

Table 9 shows relative degree of closeness of energy storage alternatives according to five different scenarios. Table 10 represents the rankings of alternatives. 
Table 9. Final results of alternatives according to scenarios

\begin{tabular}{|l|c|c|c|c|c|c|}
\hline & $\begin{array}{l}\text { Compressed Air } \\
\text { Energy Storage }\end{array}$ & $\begin{array}{l}\text { Pumped Hydro } \\
\text { Energy Storage }\end{array}$ & $\begin{array}{l}\text { Battery } \\
\text { Energy } \\
\text { Storage }\end{array}$ & Flywheels & Capacitors & $\begin{array}{l}\text { Superconducting } \\
\text { Magnetic Energy } \\
\text { Storage }\end{array}$ \\
\hline $\begin{array}{l}\text { Actual } \\
\text { situation }\end{array}$ & 0.844 & 0.694 & 0.199 & 0.349 & 0.377 & 0.185 \\
\hline Scenario 1 & 0.864 & 0.668 & 0.122 & 0.259 & 0.323 & 0.138 \\
\hline Scenario 2 & 0.810 & 0.723 & 0.278 & 0.409 & 0.422 & 0.216 \\
\hline Scenario 3 & 0.863 & 0.554 & 0.173 & 0.467 & 0.441 & 0.161 \\
\hline Scenario 4 & 0.838 & 0.757 & 0.208 & 0.287 & 0.351 & 0.192 \\
\hline Scenario 5 & 0.902 & 0.593 & 0.115 & 0.354 & 0.365 & 0.127 \\
\hline
\end{tabular}

Table 10. The ranking of alternatives according to scenarios

\begin{tabular}{|l|c|c|c|c|c|c|}
\hline & $\begin{array}{l}\text { Compressed Air } \\
\text { Energy Storage }\end{array}$ & $\begin{array}{l}\text { Pumped Hydro } \\
\text { Energy Storage }\end{array}$ & $\begin{array}{l}\text { Battery } \\
\text { Energy } \\
\text { Storage }\end{array}$ & Flywheels & Capacitors & $\begin{array}{c}\text { Superconducting } \\
\text { Magnetic Energy } \\
\text { Storage }\end{array}$ \\
\hline $\begin{array}{l}\text { Actual } \\
\text { situation }\end{array}$ & 1 & 2 & 5 & 4 & 3 & 6 \\
\hline Scenario 1 & 1 & 2 & 6 & 4 & 3 & 5 \\
\hline Scenario 2 & 1 & 2 & 5 & 4 & 3 & 6 \\
\hline Scenario 3 & 1 & 2 & 5 & 3 & 4 & 6 \\
\hline Scenario 4 & 1 & 2 & 5 & 4 & 3 & 6 \\
\hline Scenario 5 & 1 & 2 & 6 & 4 & 3 & 5 \\
\hline
\end{tabular}

According to Table 10, The alternative "Compressed Air Energy Storage" is always the best alternative for energy storage. By the way, the alternative "Pumped Hydro Energy Storage" is always the next alternative for energy storage. If the weight of "Capital cost" has been increased, the rankings of "Battery Energy Storage" and "Superconducting Magnetic Energy Storage" are changed with each other. If the weight of "Human health impacts" has been increased, the rankings of "Flywheels" and "Capacitors" are changed.

\section{Conclusion}

There are different factors that should be considered while deciding on the best electrical energy storage alternatives. Under different situations the most appropriate technology can be changed. Therefore, electrical energy storage selection problem is a multicriteria decision making problem. In this paper a two stage integrated multi criteria decision making methodology based on type-2 fuzzy sets is proposed to select the best electrical energy storage technology. The originality of this study is to use a hybrid MCDM methodology based on type-2 fuzzy sets for determining the best electrical energy storage alternatives. Using fuzzy sets help to obtain more sensitive results and with fuzzy numbers the definitions can be done more easily. In this paper the proposed hybrid methodology has been used to determine the most suitable energy storage alternative. For this aim, 6 different alternative technologies are considered with a hierarchical structure consists of 4 main criteria and 16 sub-criteria. The weights of criteria are calculated by using type- 2 fuzzy AHP and the alternatives are evaluated by using type- 2 fuzzy TOPSIS. According to results obtained, "Compressed Air Energy Storage" technology is determined the best electrical energy storage alternative. Then a sensitivity analysis is conducted to analyze the effects of subcriteria weights on the alternatives. "Capital cost" and "Human health impacts" sub-criteria weights are changed the results are analyzed. Increasing and decreasing these sub-criteria weights did not change the best and the second best alternatives. "Compressed Air Energy Storage" technology is determined in all situations by far the best alternative. In the future research, other MCDM methodologies based on type-2 fuzzy sets can be applied to the same problem and the results can be compared with the obtained results in this study.

\section{References}

1. T. Kousksou, P.Bruel, A.Jamil, T.Elrhafiki and Y. Zeraouli, Energy storage: Applications and challenges, Solar Energy Materials\&Solar Cells, (120) (2014) 5980.

2. A. Bagdanavicius and N. Jenkins, Exergy and exergoeconomic analysis of a Compressed Air Energy Storage combined with a district energy system, Energy Conversion and Management (77) (2014) 432-440.

3. S. Sundararagavan and E. Baker, Evaluating energy storage technologies for wind power integration, Solar Energy (86) (2012) 2707-2717.

4. A. Arabali, M. Ghofrani and M.E.-Amoli, Cost analysis of a power system using probabilistic optimal power 


\section{B. Ozkan et al.}

flow with energy storage integration and wind generation, Electrical Power and Energy Systems (53) (2013) 832-841.

5. B. Vahdani, R. Tavakkoli-Moghaddam, S. Meysam Mousaviand A. Ghodratnama, Soft computing based on new interval-valued fuzzy modified multi-criteria decision-making method, Applied Soft Computing (13) (2013) $165-172$.

6. S.D. Pohekar and M. Ramachandran, Application of multi-criteria decision making to sustainable energy planning - A review, Renewable and Sustainable Energy Reviews, (8) (2004) 365-381.

7. S.-C. Hsu, Tien-Chin Wang, (2001). Solving multicriteria decision making with incomplete linguistic preference relations, Expert Systems with Applications $38,10882-10888$.

8. R.A. Krohling and T.T.M. de Souza, Combining prospect theory and fuzzy numbers to multi-criteria decision making, Expert Systems with Applications 39 (2012) 11487-11493.

9. İ. Kaya, Evaluation of outsourcing alternatives under fuzzy environment for waste management, Resources, Conservation and Recycling 60 (2012) 107- 118.

10. N.N. Karnik and J.M. Mendel, Operations on type-2 fuzzy sets, Fuzzy Sets and Systems 122 (2001) 327-348.

11. J. Hu , Y. Zhang, X. Chenand Y. Liu, Multi-criteria decision making method based on possibility degree of interval type-2 fuzzy number, Knowledge-Based Systems 43 (2013) 21-29.

12. H. Chen, T.N. Cong, W. Yang, C. Tan, Y. Li and Y. Ding, Progress in electrical energy storage system: A critical review, Progress in Natural Science 19 (2009) 291-312.

13. A. Chatzivasileiadi, E. Ampatzi and I. Knight, Characteristics of electrical energy storage technologies and their applications in buildings, Renewable and Sustainable Energy Reviews 25 (2013) 814-830.

14. H.L. Ferreira, R. Garde, G. Fulli, W. Kling and J.P. Lopes, Characterisation of electrical energy storage Technologies, Energy 53 (2013) 288-298.

15. S. Karellas, N. Tzouganatos, Comparison of the performance of compressed-air and hydrogen energy storage systems: Karpathos island case study, Renewable and Sustainable Energy Reviews 29 (2014) 865-882.

16. S.M. Schoenung, Characteristics and Technologies for Long-vs. Short-Term Energy Storage, A Study by the DOE Energy Storage Systems Program, SANDIA REPORT, Unlimited Release Printed March 2001.

17. J.M. Mendel and R.I.B. John, Type-2 Fuzzy Sets Made Simple, IEEE Transactions on Fuzzy Systems, 10(2) (2002) 117-127.

18. J.M. Mendel, R.I. John, F.L. Liu. Interval type-2 fuzzy logical systems made simple, IEEE Transactions on Fuzzy Systems, 14(6) (2006) 808-821.
19. S.-M. Chen, L.-W. Lee, Fuzzy multiple attributes group decision-making based on the interval type-2 TOPSIS method, Expert Systems with Applications 37 (2010) 2790-2798

20. L.W. Lee and S.M. Chen, Fuzzy multiple attribute group decision-making based on the extension of TOPSIS method and interval type- 2 fuzzy sets. In Proceedings of the 2008 international conference on machine learning and cybernetic (2008) 3260-3265,

21. T. Daim, X. Li, J. Kim, S. Simms S. Evaluation of energy storage technologies for integration with renewable electricity: Quantifying expert opinions, Environmental Innovation and Societal Transitions, (3) (2012) 29-49.

22. M. Kiliç, İ. Kaya. Investment project evaluation by a decision making methodology based on type-2 fuzzy sets. Applied Soft Computing, 27 (2015) 399-410.

23. F.Çebi, İ. Otay. Multi-Criteria and Multi-Stage Facility Location Selection under Interval Type-2 Fuzzy Environment: A Case Study for a Cement Factory. International Journal of Computational Intelligence Systems, 8:2 (2015), 330-344,

24. M. Erdogan, İ. Kaya. An integrated multi-criteria decision making methodology based on type-2 fuzzy sets for selection among energy alternatives in Turkey. Iran. J. Fuzzy Syst. (2015) (in press).

25. C. Kahraman, B. Öztayşi, İ.U. Sarı, E. Turanoğlu. Fuzzy analytic hierarchy process with interval type-2 fuzzy sets. Knowledge-Based Systems 59 (2014) 48-57.

26. T-Y. Chen. An ELECTRE-based outranking method for multiple criteria group decision making using interval type-2 fuzzy sets. Information Sciences, 263 (2014) 121.

27. L. Abdullah, L. Najib. A new type-2 fuzzy set of linguistic variables for the fuzzy analytic hierarchy process. Expert Systems with Applications, 41 (2014) 3297-3305.

28. T-Y. Chen, C-H. Chang, J-F. R. Lu. The extended QUALIFLEX method for multiple criteria decision analysis based on interval type-2 fuzzy sets and applications to medical decision making. European Journal of Operational Research, 226(2013) 615-625.

29. M. Kiliç, İ. Kaya. The prioritisation of provinces for public grants allocation by a decision-making methodology based on type-2 fuzzy sets. Urban Studies, 2015, 1-20, doi: 10.1177/0042098014566370.

30. İ. Kaya. The process incapability index under fuzziness with an application for decision making. International Journal of Computational Intelligence Systems, 7(1) (2014), 114-128.

31. M. Erdogan, İ. Kaya. Evaluating of alternative-fuel busses for public transporta-tion in Istanbul using interval type-2 fuzzy AHP and TOPSIS, Journal of Multiple Valued Logic and Soft Computing, (2015) (in press). 